\title{
Lanthanum-Doped Ceria Nanocomposite: A Highly Stable Monolithic Catalyst for Direct Synthesis of Dimethyl Carbonate
}

\author{
Wei Chen, Zhongbin Ye*, Yue Li, Nanjun Lai, Zhaohua Song, Yongdong Chen ${ }^{*}$ \\ College of Chemistry and Chemical Engineering, Southwest Petroleum University, Chengdu, China \\ Email address: \\ yezb@swpu.edu.cn (Zhongbin Ye), yongdongchen@swpu.edu.cn (Yongdong Chen) \\ ${ }^{*}$ Corresponding author
}

\section{To cite this article:}

Wei Chen, Zhongbin Ye, Yue Li, Nanjun Lai, Zhaohua Song, Yongdong Chen. Lanthanum-Doped Ceria Nanocomposite: A Highly Stable Monolithic Catalyst for Direct Synthesis of Dimethyl Carbonate. Journal of Energy, Environmental \& Chemical Engineering.

Vol. 5, No. 4, 2020, pp. 57-66. doi: 10.11648/j.jeece.20200504.12

Received: December 1, 2020; Accepted: December 22, 2020; Published: December 31, 2020

\begin{abstract}
That dimethyl carbonate is directly synthesized from methanol and carbon dioxide is an effective and environmental approach to solve the greenhouse effect. For the sake of solving the problems of low DMC productivity and poor catalysts stability in presence of the formed water. Here we design and prepare a serial of spherical La-doped ceria nanoparticles $\left(\mathrm{Ce}_{1-\mathrm{x}} \mathrm{La}_{\mathrm{x}} \mathrm{O}_{\delta}\right.$ nanocomposites, $\mathrm{x}=0.00,0.05,0.10,0.15$, and 0.20$)$ via a co-precipitation method. These $\mathrm{Ce}_{1-\mathrm{x}} \mathrm{La}_{\mathrm{x}} \mathrm{O}_{\delta}$ composites are ground into slurry by ball milled and then coated on cordierite honeycomb ceramics to obtain $\mathrm{Ce}_{1-\mathrm{x}} \mathrm{La}_{\mathrm{x}} \mathrm{O}_{\delta}$ monolithic catalysts. These $\mathrm{Ce}_{1-\mathrm{x}} \mathrm{La}_{\mathrm{x}} \mathrm{O}_{\delta}$ composites are characterized extensively by TEM, XRD, Raman spectroscopy, $\mathrm{N}_{2}$ adsorption-desorption isotherms, $\mathrm{H}_{2}$-TPR and XPS. The characterization results show that the $\mathrm{Ce}_{1-\mathrm{x}} \mathrm{La}_{\mathrm{x}} \mathrm{O}_{\delta}$ composites nanoparticles possesses richer surface oxygen vacancies, higher BET surface area and smaller particle size than that of pure $\mathrm{CeO}_{2}$ nanoparticle. Besides, catalytic activity test shows these $\mathrm{Ce}_{1-\mathrm{x}} \mathrm{La}_{\mathrm{x}} \mathrm{O}_{\delta}$ monolithic catalysts exhibit better catalytic performance than that of pure $\mathrm{CeO}_{2}$ nanoparticles. Among them, $\mathrm{Ce}_{0.95} \mathrm{La}_{0.05} \mathrm{O}_{\delta}$ monolithic catalyst exhibits the highest $\mathrm{CH}_{3} \mathrm{OH}$ conversion and $\mathrm{DMC}$ yield, which is in good line with the oxygen vacancy content measured by XPS. Finally, the $\mathrm{Ce}_{0.95} \mathrm{La}_{0.05} \mathrm{O}_{\delta}$ monolithic catalyst also shows an excellent durability of more than 100 hours, which is mainly due to the doping effect of lanthanum into the ceria oxides tailoring the structure and surface properties of the catalyst.
\end{abstract}

Keywords: La-doped $\mathrm{CeO}_{2}$ Nanoparticles, Dimethyl Carbonate, Monolithic Catalysts, High Durability, $\mathrm{CO}_{2}$ Utilization

\section{Introduction}

With the development of industry and extensive use of petrochemical resources, the increased greenhouse gas emissions have caused shocking climate change, which causes huge environmental problems [1], such as global warming. Carbon dioxide $\left(\mathrm{CO}_{2}\right)$, one of the most important greenhouse gases causing global warming, is a potential carbon resource as well [2]. Therefore, utilizing greenhouse gas $\mathrm{CO}_{2}$ as an effective carbon resource for fixation and resource utilization is of great significance in alleviating the crisis of carbon sources and environmental protection [1].

Dimethyl carbonate (DMC), as a chemical raw material with low toxicity, excellent environmental protection performance as well as wide application, has broad potential application prospects [3]. It can replace traditional carbonylation and methylation reagent and avoid the toxicity of phosgene, methyl chloroformate and dimethyl sulfate [4-7]. In addition, as a gasoline additive, DMC can improve its octane number and oxygen content, thus improving its antiknock performance [4, 6-8]. Based on the wide application and large demand of DMC, researchers recently have discovered a series of methods for the DMC synthesis, including carbonylation of methanol $[9,10]$, transesterification of carbonates [11, 12], alcoholysis of urea [13] and direct synthesis from $\mathrm{CO}_{2}$ and methanol [14-17]. Among all of these routes, $\mathrm{CO}_{2}+2 \mathrm{CH}_{3} \mathrm{OH} \rightarrow$ $\mathrm{CH}_{3} \mathrm{OC}(=\mathrm{O}) \mathrm{OCH}_{3}+\mathrm{H}_{2} \mathrm{O}$, this synthesis method has gradually become the most attractive method, which can realize the efficient use of the greenhouse gas $\mathrm{CO}_{2}$ [17]. However, this direct synthetic method still faces some problems to be solved 
urgently. The productivity of dimethyl carbonate is relatively low (e.g., $<5 \%$ ) due to the kinetic inertness and high thermodynamic stability of $\mathrm{CO}_{2}$, as well as the by-product water can easily inactivate the catalyst [16], which leads to the poor reaction stability during the DMC synthesis. Therefore, we consider to overcome these problems by developing novel catalysts to effectively remove the generated water in the reaction system to improve the stability of the catalysts.

It has been reported that many nano-catalysts were effective for increasing the yield of this reaction, such as supported $\mathrm{Cu}-\mathrm{Ni}$ bimetallic catalysts [18-20], organometallic compounds [21], zirconium oxide [22], cerium oxide [23, 24], $\mathrm{CeO}_{2}-\mathrm{ZrO}_{2}[5,25$, $26]$, and so on. According to the catalysts reported in the literature, transition metal-doped ceria catalysts showed excellent catalytic activity [5]. For example, Wang et al. [27] observed that the exposed crystal plane, defect sites and acid-base sites had a crucial impact on the well-defined $\mathrm{CeO}_{2}$ nanocrystal catalyst. In addition, researchers also observed that doping transition metal elements (such as $\mathrm{Ti}[14,16], \mathrm{Zn}[28], \mathrm{Ca}[29,30]$, and $\mathrm{La} \mathrm{[23])} \mathrm{into} \mathrm{CeO}_{2}$ will affect its storage/release oxygen capacity, defects stability as well as oxygen atom mobility, and thus to improve the catalytic activity and thermal stability of the catalyst.

Although the ceria-based catalysts have excellent catalytic performance for the DMC direct synthetic method compared with other catalysts, the $\mathrm{CH}_{3} \mathrm{OH}$ conversion is still low (e.g., $<5 \%$ ), which seriously hinders its real application. This is mainly due to the water formed during the catalytic reaction can't be removed in time, so that the equilibrium of the reversible reaction shifts to the reverse reaction direction (according to Le Chatelier's principle) [14]. As a result, adding a dehydrating agent such as 2-cyanopyridine is of great necessity for high methanol conversion and DMC productivity [23]. However, dehydrating agents are generally expensive, highly toxic, and environmentally unfriendly. Therefore, to develop a low-cost, effecient and water-resistant catalyst to enhance the catalytic activity is worthwhile and urgently needed.

In this work, we prepare lanthanum-doped $\mathrm{CeO}_{2}$ nanoparticles through a co-precipitation method. Nanocomposites of $\mathrm{Ce}_{1-\mathrm{x}} \mathrm{La}_{\mathrm{x}} \mathrm{O}_{\delta}$ (where, $\mathrm{x}=0.00,0.05,0.10$, 0.15 , and 0.20 ) are coated on a honeycomb ceramic substrate to form $\mathrm{Ce}_{1-\mathrm{x}} \mathrm{La}_{\mathrm{x}} \mathrm{O}_{\delta}$ monolithic catalysts for the direct synthesis of DMC. The monolithic catalysts have the virtue of lower pressure drop, larger BET surface area, better mechanical stability and thermal stability in compression to corresponding particulate catalysts $[14,31,32]$. In addition, the reaction products (water and DMC) produced by this reaction can be removed in time to improve the catalytic performance. The experimental results show that the lanthanum doped ceria monolithic catalysts exhibit excellent catalytic activity and great stability in DMC direct synthetic method in the absence of any dehydrating agents.

\section{Experimental}

\subsection{Materials}

All the reactants were analytical purity and used without any further treatment except methanol was Chromatographically purity. Cerium ammonium nitrate $\left(\left(\mathrm{NH}_{4}\right)_{2} \mathrm{Ce}\left(\mathrm{NO}_{3}\right)_{6} \cdot 6 \mathrm{H}_{2} \mathrm{O}\right)$ and Lanthanum nitrate $\left(\mathrm{La}(\mathrm{NO})_{3} \cdot 6 \mathrm{H}_{2} \mathrm{O}\right)$ were purchased from Aladdin Co., Ltd. (Shanghai, China). Ethanol and urea were purchased from Chengdu Kelong Chemical Reagent Factory (Chengdu, China), Methanol ( $\geq 99.9 \%$ ) was purchased from Shanghai Titan Technology Co., Ltd. (Shanghai, China). $\mathrm{CO}_{2}$ $(\geq 99.9 \%)$ and $\mathrm{N}_{2}(\geq 99.9 \%)$ were obtained from Chengdu Xindu District Zhengrong Gas Co., Ltd. (Chengdu, China).

\subsection{Preparation of $\mathrm{Ce}_{1-x} \mathrm{La}_{x} \mathrm{O}_{\delta}$ Monolith Catalysts}

$\mathrm{Ce}_{1-\mathrm{x}} \mathrm{La}_{\mathrm{x}} \mathrm{O}_{\delta}$ nanoparticles were synthesized through co-precipitation method. The specific method for synthesis of $\mathrm{Ce}_{0.8} \mathrm{La}_{0.2} \mathrm{O}_{\delta}$ nanoparticles was as follows: $15.00 \mathrm{~g}$ of $\left(\mathrm{NH}_{4}\right)_{2} \mathrm{Ce}\left(\mathrm{NO}_{3}\right)_{6} \cdot 6 \mathrm{H}_{2} \mathrm{O}$ and $2.96 \mathrm{~g}$ of $\mathrm{La}(\mathrm{NO})_{3} \cdot 6 \mathrm{H}_{2} \mathrm{O}$ were dissolved in deionized water to form a solution, which was mixed with the preformed urea aqueous solution prepared by $70 \mathrm{~g}$ urea and transferred the mixture to a $1000 \mathrm{~mL}$ three-necked flask. The mixture was naturally heated in water bath to $90{ }^{\circ} \mathrm{C}$ for 5 hours under mechanical stirring. After the reaction, it was cooled, filtered, and washed with pure water and ethanol for several times. The collected precipitate was dried at $80{ }^{\circ} \mathrm{C}$ for more than $12 \mathrm{~h}$ and subsequently calcined at $400{ }^{\circ} \mathrm{C}$ for $4 \mathrm{~h}$ to obtain $\mathrm{Ce}_{0.8} \mathrm{La}_{0.2} \mathrm{O}_{\delta}$ nanoparticles. $\mathrm{Ce}_{1-\mathrm{x}} \mathrm{La}_{\mathrm{x}} \mathrm{O}_{\delta}$ $(0 \leq \mathrm{x} \leq 0.20)$ nanoparticles with different La dopants were prepared by changing the amounts of $\left(\mathrm{NH}_{4}\right)_{2} \mathrm{Ce}\left(\mathrm{NO}_{3}\right)_{6} \cdot 6 \mathrm{H}_{2} \mathrm{O}$ and $\mathrm{La}(\mathrm{NO})_{3} \cdot 6 \mathrm{H}_{2} \mathrm{O}$ in the starting solution.

Firstly, the as-obtained $\mathrm{Ce}_{1-\mathrm{x}} \mathrm{La}_{\mathrm{x}} \mathrm{O}_{\delta}$ nanoparticles powder was milled with appropriate amount of pseudo-boehmite, deionized water and glacial acetic acid to prepare a slurry. Then, the cordierite honeycomb ceramic substrate (Figure 1, left), which has been manually polished into a specific shape, was immersed in the slurry, and the excess slurry was blown off with compressed air. Ultimately, the coated catalyst was dried at $80^{\circ} \mathrm{C}$ overnight and calcined at $400^{\circ} \mathrm{C}$ for 4 hours to obtain a $\mathrm{Ce}_{1-\mathrm{x}} \mathrm{La}_{\mathrm{x}} \mathrm{O}_{\delta}$ monolith catalyst (Figure 1, right). The dried coating quality of $\mathrm{Ce}_{1-\mathrm{x}} \mathrm{La}_{\mathrm{x}} \mathrm{O}_{\delta}$ had a mass of about $0.5 \mathrm{~g}$.
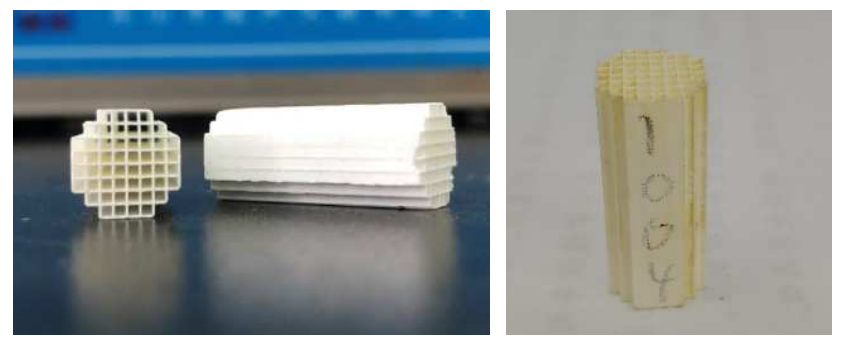

Figure 1. The appearance picture of cordierite honeycomb ceramic substrate (left) and monolithic catalyst (right, cordierite honeycomb ceramic substrate coated with $\mathrm{Ce}_{0.95} L a_{0.05} \mathrm{O}_{\delta}$ nanoparticle). The pore density of cordierite honeycomb ceramic matrix $\geq 400$ cpsi.

\subsection{Characterization Techniques}

Transmission electron microscopy (TEM) was used to observe the micro morphology of the catalyst and measure the particle size. The TEM characterization was performed on a Philips FEI Tecnai G2 Sprit F30S-Twin transmission electron microscope with at an acceleration voltage of $120 \mathrm{kV}$. Sample 
preparation process: firstly, the sample was ground into powder with an agate mortar, and then the ground sample was evenly dispersed in absolute ethanol, and then the suspension was dropped on the carbon film of copper mesh and dried in the air for testing. The particle size of these samples was determined by a random selection of $>400$ particles in different area of the TEM images. X-ray diffraction (XRD) was used to identify and analyze the phase, cell parameters and crystal form of the catalytic materials. Firstly, the samples were ground and pressed, and then put into a X Pert PRO MPD diffract meter (PANalytical B. V.) for X-ray diffraction analysis with a $\mathrm{Cu} \mathrm{K} \alpha$ ray $(\lambda=0.15418 \mathrm{~nm})$ operated at $40 \mathrm{kV}$ and $200 \mathrm{~mA}$. The scanning range was $20^{\circ} \sim 80^{\circ}$ and the intensity was recorded by scintillation counter. The crystal phases were identified based on JCPDS card and Jade-6.5 X ray data processing software was used for data processing.

$\mathrm{N}_{2}$ adsorption-desorption isotherms were measured on a Quanta chrome autos orb iQ instrument. Nitrogen was used as the adsorbed gas, and the analysis temperature was liquid nitrogen temperature. The sample was purged at $90{ }^{\circ} \mathrm{C}$ for $1 \mathrm{~h}$, then vacuum pretreated at $300{ }^{\circ} \mathrm{C}$ for $3 \mathrm{~h}$, and then cooled to room temperature for BET test. The specific surface area is calculated by the BET method, and the pore structure distribution map is obtained by the BJH method.

Raman spectra were recorded by a Renishaw in Via Raman spectrometer. The scanning wavelength range is 100-1000 $\mathrm{cm}^{-1}$. The light source is visible light source, and the wavelength is $532 \mathrm{~nm}$.

The temperature-programmed reduction by hydrogen $\left(\mathrm{H}_{2}\right.$-TPR) of the catalyst was carried out in an AutochemII2920 instrument (Micromeritics) with a conventional TCD detector. Firstly, $100 \mathrm{mg}$ of the sample was placed in a U-shaped quartz tube, and the sample was cleaned with $30 \mathrm{ml} \mathrm{min}$ argon at $200^{\circ} \mathrm{C}$ for $30 \mathrm{~min}$. After cooling to $30^{\circ} \mathrm{C}$ under an argon atmosphere $(30 \mathrm{~mL} / \mathrm{min}), 10 \% \mathrm{H}_{2} / \mathrm{Ar}(30$ $\mathrm{mL} / \mathrm{min}$ ) was introduced to the system and the temperature was programmed at a rate of $10^{\circ} \mathrm{C} / \mathrm{min}$ to $900^{\circ} \mathrm{C}$. The signal was recorded with a thermal conductivity detector, and finally dropped to room temperature.

The XPS characterization was analyzed by a Theta Probe system (Thermo Scientific) photoelectron spectroscopy using Al Karadiation at $13 \mathrm{KV}$ and $20 \mathrm{~mA}$. The electro binding energy was corrected by the $\mathrm{C} 1 \mathrm{~s}(284.8 \mathrm{eV})$ contaminated carbon. To analyze the individual contributions of the Ce $3 \mathrm{~d}$ and $\mathrm{O} 1 \mathrm{~s}$ core levels, the absorption peaks of $\mathrm{Ce} 3 \mathrm{~d}$ and $\mathrm{O} 1 \mathrm{~s}$ were fitted. According to equation (1) and (2), the concentration of $\mathrm{Ce}^{3+}\left(C\left[\mathrm{Ce}^{3+}\right] \%\right)$ and surface oxygen vacancies $\left(C\left[\mathrm{O}_{V}\right] \%\right)$ of $\mathrm{Ce}_{1-\mathrm{x}} \mathrm{La}_{\mathrm{x}} \mathrm{O}_{\delta}$ catalysts were calculated by semi-quantitative analysis of the integral peak area of respective valence state.

$$
\begin{aligned}
& C\left[\mathrm{Ce}^{3+}\right] \%=\frac{S_{C e^{3+}}}{S_{C e^{3+}+S_{C e^{4+}}}} \times 100 \%, \\
& S_{C e^{3+}}=S_{v^{\prime}}+S_{u^{\prime}} S_{C e^{4+}}=S_{v}+S_{v^{\prime \prime}}+S_{v^{\prime \prime \prime}}+S_{u}+S_{u^{\prime \prime}}+S_{u^{\prime \prime \prime}} \\
& C\left[O_{v}+O_{c}\right] \%=\frac{S_{O_{v}}+S_{O_{c}}}{S_{O_{v}}+S_{O_{c}}+S_{O_{L}}},
\end{aligned}
$$

$\mathrm{S}_{\mathrm{Ce}}{ }^{3+}$ : Sum of peak areas of $\mathrm{Ce}^{3+}$ on catalyst surface;

$\mathrm{S}_{\mathrm{Ce}}{ }^{4+}$ : Sum of peak areas of $\mathrm{Ce}^{4+}$ on catalyst surface

$\mathrm{S}_{\mathrm{OL}}$ : Lattice oxygen area of catalyst surface.

$\mathrm{S}_{\mathrm{Oc}}$ : Area of chemically adsorbed oxygen on catalyst surface.

$\mathrm{S}_{\mathrm{Ov}}$ : Oxygen vacancy area on catalyst surface.[1].

\subsection{Catalytic Performance Test}

Direct synthesis DMC from $\mathrm{CO}_{2}$ and $\mathrm{CH}_{3} \mathrm{OH}$ was carried out in a continuous fixed-bed reactor. The prepared monolithic $\mathrm{Ce}_{1-\mathrm{x}} \mathrm{La}_{\mathrm{x}} \mathrm{O}_{\delta}$ catalyst was placed into a stain reactor tube and sealed, and then purged with $\mathrm{CO}_{2}$ flow for more than $10 \mathrm{~min}$ to drain the internal air. After the reaction system was heated to the required temperature, a constant current pump was used to introduce $\mathrm{CH}_{3} \mathrm{OH}$ into the system to participate in the reaction. During the experiment, the flow rate of $\mathrm{CO}_{2}\left(40 \mathrm{~mL} \cdot \mathrm{min}^{-1}\right)$ and $\mathrm{CH}_{3} \mathrm{OH}\left(0.145 \mathrm{~mL} \cdot \mathrm{min}^{-1}\right.$, it is calculated from the molar ratio of $\mathrm{CH}_{3} \mathrm{OH}$ : $\mathrm{CO}_{2}=2: 1$ and the flow of $\mathrm{CO}_{2}$ ) remained constant, which can be precisely controlled by evaporating $\mathrm{CH}_{3} \mathrm{OH}$ and $\mathrm{CO}_{2}$ flow. The tail gas component after the reaction was analyzed online using a gas chromatography instrument (Agilent GC 7890B) equipped with a hydrogen flame ionization detector (FID) for the detections of organic species (e.g. $\mathrm{CH}_{3} \mathrm{OH}, \mathrm{DMC}, \mathrm{HCHO}, \mathrm{DME}$, et al.) and a thermal conductivity detector (TCD) for $\mathrm{CO}$ and $\mathrm{CO}_{2}[2,3]$. The calculation formula for $\mathrm{CH}_{3} \mathrm{OH}$ conversion (conversion) and DMC selectivity is:

$$
\mathrm{CH}_{3} \mathrm{OH} \text { conv. }(\%)=\frac{3 C_{D M C}+2 C_{D M E}+C_{H C H O}+C_{C O}}{C_{C H 3 O H}+3 C_{D M C}+2 C_{D M E}+C_{H C H O}+C_{C O}} \times 100 \%
$$

$$
\text { DMC sel. }(\%)=\frac{3 C_{D M C}}{3 C_{D M C}+2 C_{D M E}+C_{H C H O}+C_{C O}} \times 100 \%
$$

where, $C_{\mathrm{i}}$ represents the concentration of a component $(i)$.

\section{Results and Discussion}

\subsection{Characterization of $\mathrm{Ce}_{1-x} \mathrm{La}_{x} \mathrm{O}_{\delta}$ Composites}

The microstructure and the size distribution of the
$\mathrm{Ce}_{1-\mathrm{x}} \mathrm{La}_{\mathrm{x}} \mathrm{O}_{\delta}(\mathrm{x}=0.00,0.05,0.10,0.15$, and 0.20$)$ nanoparticles are depicted in Figure 2, respectively. It is noted that the diameter of $\mathrm{Ce}_{1-\mathrm{x}} \mathrm{La}_{\mathrm{x}} \mathrm{O}_{\delta}$ nanoparticles varies from $3 \sim 7 \mathrm{~nm}$ with the molar ratios of $\mathrm{La} / \mathrm{Ce}$. In addition, we can also notice with the increasing concentration of lanthanum dopant, the size of the $\mathrm{Ce}_{1-\mathrm{x}} \mathrm{La}_{\mathrm{x}} \mathrm{O}_{\delta}$ nanoparticles slightly decrease from $6.8 \mathrm{~nm}$ $\left(\mathrm{CeO}_{2}\right)$ to $3.8 \mathrm{~nm}\left(\mathrm{Ce}_{0.80} \mathrm{La}_{0.20} \mathrm{O}_{\delta}\right)$. This phenomenon is in good line with XRD results (Figure $3 \mathrm{a}$ and Table 1). 

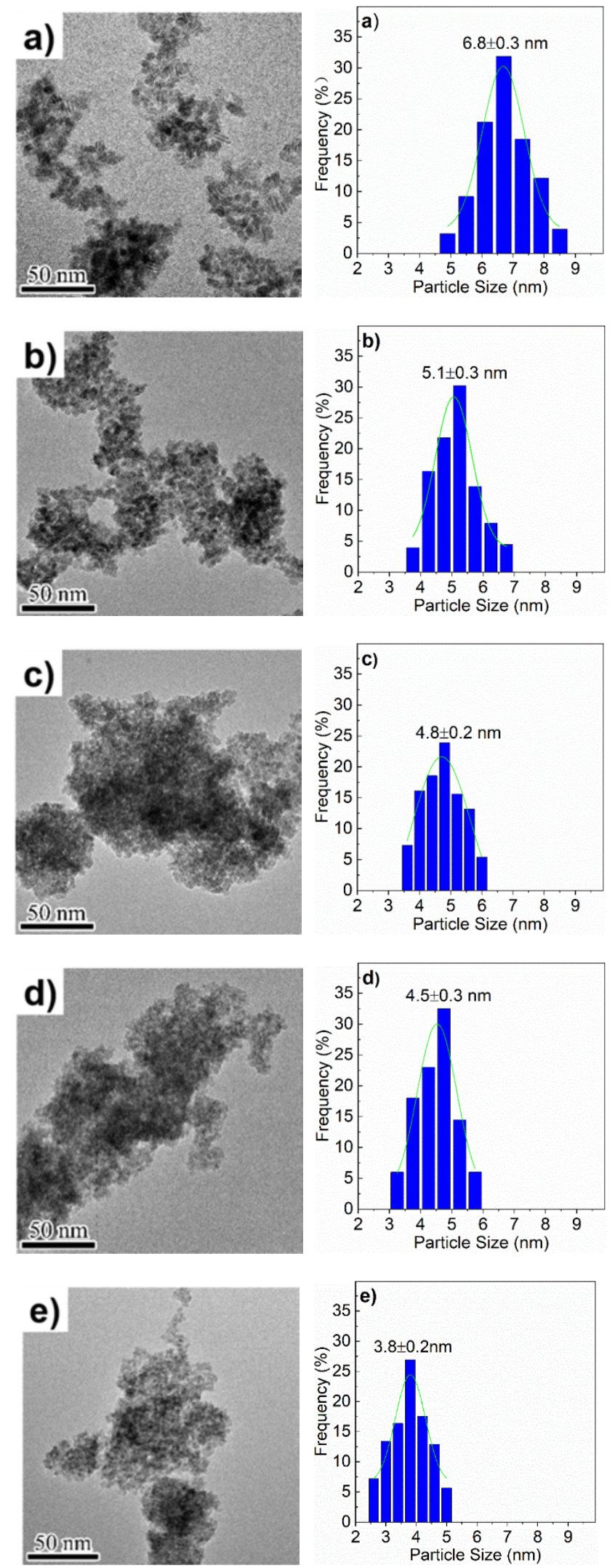

Figure 2. TEM and particle size distribution images of $C e_{1-x} L a_{x} O_{\delta}$ nanoparticles.

Figure 3a shows the XRD patterns of the $\mathrm{Ce}_{1-\mathrm{x}} \mathrm{La}_{\mathrm{x}} \mathrm{O}_{\delta}$ nanoparticles. Obviously, lanthanum doped ceria composites showed four diffraction peaks in the range of $2 \theta=20 \sim 60$, where $2 \theta=28.5^{\circ}, 33.0^{\circ}, 47.4^{\circ}$, and $56.2^{\circ}$, which were just corresponding to (111), (200), (220) and (311) crystal planes of $\mathrm{CeO}_{2}$. [14]. Further, no peaks are observed corresponding to individual lanthanum oxide, which can be explained by the formation of $\mathrm{Ce}_{1-\mathrm{x}} \mathrm{La}_{\mathrm{x}} \mathrm{O}_{\delta}$ solid solution. Figure $3 \mathrm{~b}$ shows that the $\mathrm{Ce}_{1-\mathrm{x}} \mathrm{La}_{\mathrm{x}} \mathrm{O}_{\delta}$ nanoparticles exhibit broader (111) diffraction peak which shift to lower $2 \theta$ with the increasing concentration of lanthanum species. Moreover, we also notice the (111) lattice parameter of $\mathrm{Ce}_{1-\mathrm{x}} \mathrm{La}_{\mathrm{x}} \mathrm{O}_{\delta}$ nanoparticles increases from $0.5413 \mathrm{~nm}\left(\mathrm{CeO}_{2}\right)$ to $0.5453 \mathrm{~nm}\left(\mathrm{Ce}_{0.80} \mathrm{La}_{0.20} \mathrm{O}_{\delta}\right.$, Table 1) as a result of $\mathrm{La}^{3+}$ ion radius $(0.106 \mathrm{~nm})$ is larger than $\mathrm{Ce}^{4+}$ ion radius $(0.097 \mathrm{~nm})$. When $\mathrm{La}^{3+}$ enters in the ceria lattice to replace partial $\mathrm{Ce}^{4+}$, the lattice parameter of ceria will increase, and these changes are consistent with the previous reports [14]. All the results indicate that $\mathrm{La}^{3+}$ is successfully introduced into Ceria lattice, forming a solid solution and increasing the interplanar crystal spacing [33], which increases from $0.3127 \mathrm{~nm}$ for $\mathrm{CeO}_{2}$ nanoparticles to 0.3148 $\mathrm{nm}$ for $\mathrm{Ce}_{0.80} \mathrm{La}_{0.20} \mathrm{O}_{\delta}$ nanoparticles.
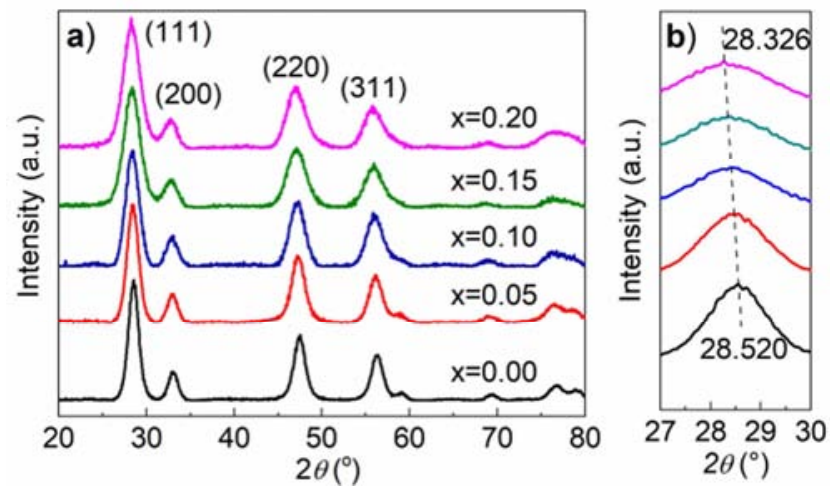

Figure 3. (a) XRD patterns of the $C e_{1-x} L a_{x} O_{\delta}$ composites. (b) Zoom-in of the (111) peak.

The adsorption equilibrium isotherms are also measured to analysze thepore volume, average pore size and specific surface area of the catalyst. From the adsorption equilibrium isotherms of the prepared $\mathrm{Ce}_{1-\mathrm{x}} \mathrm{La}_{\mathrm{x}} \mathrm{O}_{\delta}$ composite oxides, we can see all of them show type IV adsorption equilibrium isotherms and exhibit obvious $\mathrm{H}_{2}$ hysteresis loop in the IUPAC classification begins to appear with the relative pressure $\left(\mathrm{P} / \mathrm{P}_{0}\right) 0.4$ as the apex, indicating that they are typical mesoporous materials (Figure 4 ). The pore volume, average pore size and Brunauer-Emmett-Teller (BET) surface area of the synthesized $\mathrm{Ce}_{1-\mathrm{x}} \mathrm{La}_{\mathrm{x}} \mathrm{O}_{\delta}$ composites are summarized in Table 1. Obviously, the BET surface area of $\mathrm{Ce}_{1-\mathrm{x}} \mathrm{La}_{\mathrm{x}} \mathrm{O}_{\delta}$ samples increase when more lanthanum ions are induced into the ceria and $\mathrm{Ce}_{0.95} \mathrm{La}_{0.05} \mathrm{O}_{\delta}$ shows the largest pore volume and average pore size. 
Table 1. Structural and textural properties of of $C e_{1-x} L a_{x} O_{\delta}$ nanoparticles.

\begin{tabular}{|c|c|c|c|c|c|c|c|}
\hline \multirow{2}{*}{ samples } & \multicolumn{2}{|c|}{ (111) plane } & \multirow{2}{*}{$\begin{array}{l}\text { Lattice } \\
(\mathbf{n m})\end{array}$} & \multirow{2}{*}{$\begin{array}{l}\text { Crystalline } \\
\text { size }^{b}\end{array}$} & \multirow{2}{*}{$\begin{array}{l}S_{\text {BET }} \\
\left(\mathrm{m}^{2} \cdot \mathrm{g}^{-1}\right)\end{array}$} & \multirow{2}{*}{$V_{\text {Pore }}\left(\mathrm{cm}^{3} \cdot \mathrm{g}^{-1}\right)$} & \multirow{2}{*}{$\begin{array}{l}\text { Average pore size } \\
\text { (nm) }\end{array}$} \\
\hline & $2\left({ }^{\circ}\right)$ & Parameter $^{\mathrm{a}}$ & & & & & \\
\hline $\mathrm{CeO}_{2}$ & 28.520 & 0.3127 & 0.5413 & 6.8 & 142.9 & 0.141 & 3.937 \\
\hline $\mathrm{Ce}_{0.95} \mathrm{La}_{0.05} \mathrm{O}_{\delta}$ & 28.456 & 0.3134 & 0.5429 & 5.1 & 159.0 & 0.163 & 4.104 \\
\hline $\mathrm{Ce}_{0.90} \mathrm{La}_{0.10} \mathrm{O}_{\delta}$ & 28.388 & 0.3141 & 0.5437 & 4.8 & 158.6 & 0.119 & 3.003 \\
\hline $\mathrm{Ce}_{0.85} \mathrm{La}_{0.15} \mathrm{O}_{\delta}$ & 28.361 & 0.3144 & 0.5446 & 4.5 & 171.8 & 0.122 & 2.847 \\
\hline $\mathrm{Ce}_{0.80} \mathrm{La}_{0.20} \mathrm{O}_{\delta}$ & 28.326 & 0.3148 & 0.5453 & 3.8 & 186.0 & 0.160 & 3.437 \\
\hline
\end{tabular}

${ }^{a}$ The lattice parameter is calculated using Vegard's law. b The size of the oxide nanoparticles is estimated by TEM.

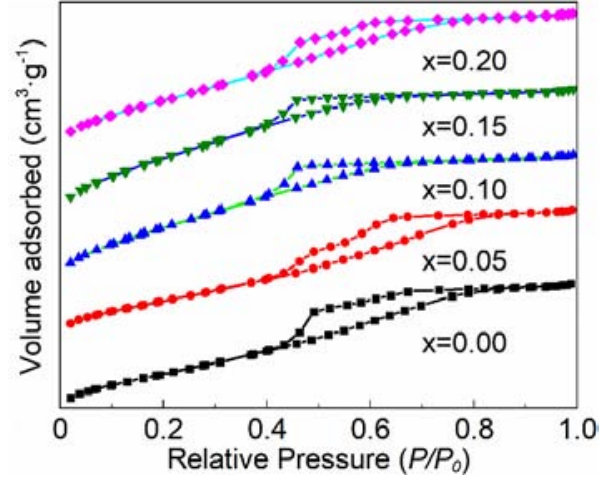

Figure 4. $\mathrm{N}_{2}$ adsorption-desorption isotherm of $C e_{1-x} L a_{x} O_{\delta}$ nanocomposites.

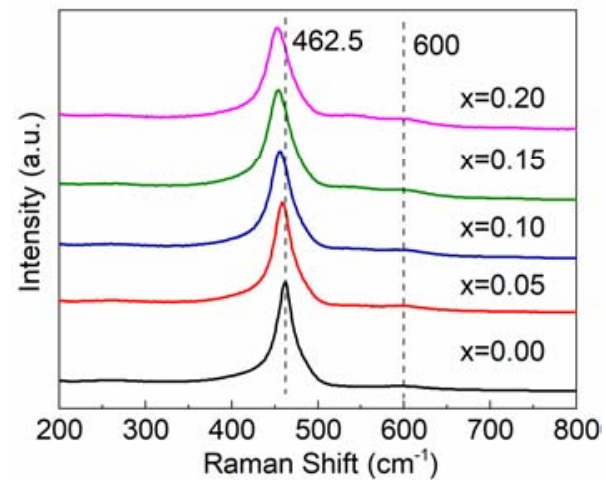

Figure 5. Raman spectra of $C e_{1-x} L a_{x} O_{\delta}$ nanoparticles

Further, the $\mathrm{Ce}_{1-\mathrm{x}} \mathrm{La}_{\mathrm{x}} \mathrm{O}_{\delta}$ nanoparticles are characterized by Raman spectroscopy, as seen in Figure 5. The sharp peak at $462.5 \mathrm{~cm}^{-1}$ is the $\mathrm{F}_{2 \mathrm{~g}}$ vibration peak of $\mathrm{Ce}-\mathrm{O}$ [34], indicating that $\mathrm{Ce}_{1-\mathrm{x}} \mathrm{La}_{\mathrm{x}} \mathrm{O}_{\delta}$ nanoparticles solid solution are cubic fluorite structure, matching well with the above XRD results. According to previous studies [35, 36], oxygen vacancies should be the catalytically active mediators during the DMC synthesis. With the increasing $\mathrm{La}^{3+}$ content, the peak intensity associated with the defect around $600 \mathrm{~cm}^{-1}$ increases slightly, indicating that the doping of $\mathrm{La}^{3+}$ promotes the formation of more defects and conforming the potential of the $\mathrm{Ce}_{1-\mathrm{x}} \mathrm{La}_{\mathrm{x}} \mathrm{O}_{\delta}$ composites for DMC production. It is further basically consistent with the XPS results. Moreover, the $F_{2 g}$ bands become asymmetric, broaden with the increasing content of $\mathrm{La}^{3+}$ increasing and gradually shift to low wavenumber compared to pure ceria, which mainly because $\mathrm{La}^{3+}$ replacing part of $\mathrm{Ce}^{4+}$ will increase the bond length of $\mathrm{Ce}-\mathrm{O}$, causing the Raman spectrum moving to lower energy [5, 37, 38]. According to the literature, we have learned that this red shift is concerned with the change of the force between atoms, which is susceptible to the lattice spacing and the change of bond length [5].

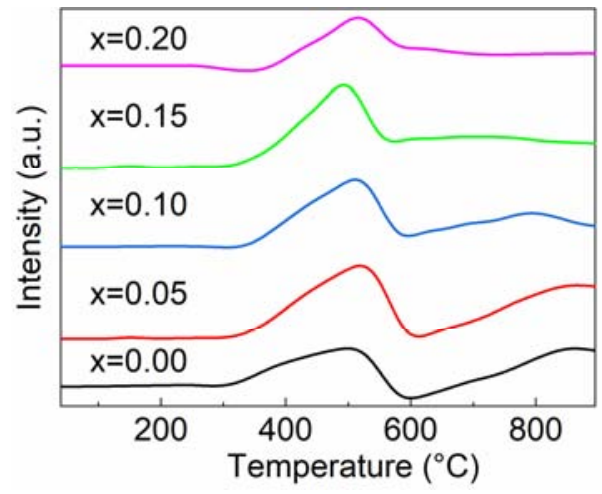

Figure 6. $H_{2}-T P R$ profiles of $C e_{1-x} L a_{x} O_{\delta}$ nanoparticles.

Next, Figure 6 shows the $\mathrm{H}_{2}$-TPR curve of the $\mathrm{Ce}_{1-\mathrm{x}} \mathrm{La}_{\mathrm{x}} \mathrm{O}_{\delta}$ nanoparticles. $\mathrm{CeO}_{2}$ nanoparticles show two obvious reduction peaks at $\sim 504^{\circ} \mathrm{C}$ and $\sim 864^{\circ} \mathrm{C}$, respectively. The reduction peak at $504^{\circ} \mathrm{C}$ is related to the surface reduction, while the peak at higher reduction temperature is ascribed to bulk reduction [39, 40]. And the surface hydrogen consumption of $\mathrm{CeO}_{2}$ nanoparticles is $0.666 \mathrm{mmol} \cdot \mathrm{g}^{-1}$. Under the condition of hydrogen reduction, oxygen species on the surface of coordination unsaturated can be easily removed at a lower temperature. However, the bulk oxygen anions can only be reduced at a relative higher temperature after being transported to the surface [33]. When $\mathrm{La}^{3+}$ is doped into ceria, the corresponding hydrogen consumption under low temperature conditions first increases and then slightly decreases. It shows the doping of an appropriate amount of $\mathrm{La}_{2} \mathrm{O}_{3}$ can increase the amount of surface oxygen species that can be removed. Moreover, we also find that $\mathrm{La}^{3+}$ doping can cause the bulk reduction peak of $\mathrm{CeO}_{2}$ move to the low temperature [41]. For $\mathrm{Ce}_{0.95} \mathrm{La}_{0.05} \mathrm{O}_{\delta}, \mathrm{Ce}_{0.90} \mathrm{La}_{0.10} \mathrm{O}_{\delta}$ and $\mathrm{Ce}_{0.85} \mathrm{La}_{0.15} \mathrm{O}_{\delta}$ nanoparticles, the bulk reduction peaks decrease to $845^{\circ} \mathrm{C} 794^{\circ} \mathrm{C}$ and $703^{\circ} \mathrm{C}$ respectively. For $\mathrm{Ce}_{0.80} \mathrm{La}_{0.20} \mathrm{O}_{\delta}$ nanoparticles, at about $513^{\circ} \mathrm{C}$, the bulk reduction peak and the surface reduction peak almost completely merge into a wide peak, which is consistent with the reported results in literature that the high temperature and low temperature reduction peaks of $\mathrm{Ce}_{1-\mathrm{x}} \mathrm{La}_{\mathrm{x}} \mathrm{O}_{\delta}$ composites gradually merged into one wide peak with the increase of lanthanum content [33]. Furthermore, $\mathrm{CeO}_{2}$ and $\mathrm{Ce}_{1-\mathrm{x}} \mathrm{La}_{\mathrm{x}} \mathrm{O}_{\delta}$ nanoparticles have the same the bulk reduction mechanism. However, the bulk reduction peak of $\mathrm{Ce}_{1-\mathrm{x}} \mathrm{La}_{\mathrm{x}} \mathrm{O}_{\delta}$ nanoparticles shifts to low temperature may be due to the relatively rapid 
diffusion of oxygen from bulk to the surface, the bulk oxide ions continue to move to the surface, forming more active hydrogen adsorption sites on the surface [41].

The chemical state of $\mathrm{Ce}$ on the surface of $\mathrm{Ce}_{1-\mathrm{x}} \mathrm{La}_{\mathrm{x}} \mathrm{O}_{\delta}$ nanoparticles is studied by XPS. As shown in Figure $7 \mathrm{a}$, the content of La has an obvious effect on the chemical state of $\mathrm{Ce}$ on the catalyst surface. According to the literature method, we can decompose the Ce $3 \mathrm{~d}$ spectrum into eight peaks [5]: $u^{\prime \prime \prime}$, $u^{\prime \prime}, u^{\prime} u, v^{\prime \prime \prime}, v^{\prime \prime}, v^{\prime}$, and $v$. The four $v$ bands belong to the spin-orbit splitting peaks of $\mathrm{Ce} 3 \mathrm{~d}_{5 / 2}$, while the other four $u$ bands are attributed to the spin-orbit splitting peaks of $\mathrm{Ce}$ $3 \mathrm{~d}_{3 / 2}$. The six peaks of $\mathrm{u}, \mathrm{u}$ ", $\mathrm{u}$ '", $v, v^{\prime \prime}$ and $\mathrm{v}^{\prime \prime}$ are the final state spin orbit splitting peaks of $\mathrm{Ce}^{4+}$, and the two peaks of $\mathrm{u}$ 'and $\mathrm{v}^{\prime}$ are the final state spin orbit splitting peaks of $\mathrm{Ce}^{3+}$, which indicates that there are two valence states of $\mathrm{Ce}$ on the surface of $\mathrm{Ce}_{1-\mathrm{x}} \mathrm{La}_{\mathrm{x}} \mathrm{O}_{\delta}$ nanoparticles. Quantitative analysis of $\mathrm{Ce}^{3+}$ on the catalyst surface is carried out and the calculation method is shown in 2.3 in Chapter 2. It is showed that the $\mathrm{Ce}^{3+}$ concentration changes with the change of lanthanum doping and $\mathrm{Ce}_{0.95} \mathrm{La}_{0.05} \mathrm{O}_{\delta}$ nanoparticles exhibit the highest $\mathrm{Ce}^{3+}$ concentration of $21.13 \%$ among all the subjects. Moreover, $\mathrm{Ce}_{1-\mathrm{x}} \mathrm{La}_{\mathrm{x}} \mathrm{O}_{\delta}$ nanoparticles exhibit higher $\mathrm{Ce}^{3+} / \mathrm{Ce}_{\text {total }}$ proportion compared with pure ceria, which indicates that the doping of La significantly increases the surface $\mathrm{Ce}^{3+}$ concentration. Zhang et al [42] has found the generation of $\mathrm{Ce}^{3+}$ leads to the formation of oxygen vacancies. As $\mathrm{Ce}^{3+}$ concentration increases, oxygen vacancies concentration increases as well [5]. As a result, $\mathrm{Ce}_{0.95} \mathrm{La}_{0.05} \mathrm{O}_{\delta}$ nanoparticles may have the highest surface oxygen vacancy concentration.

The $\mathrm{O} 1 \mathrm{~s}$ spectra of the prepared composites is shown in Figure 7b. According to the literature method, the XPS spectrum of $\mathrm{O} 1 \mathrm{~s}$ can be divided into 3 peaks after fitting: $\mathrm{O}_{\mathrm{L}}$ $(\sim 529.3 \mathrm{eV}), \mathrm{O}_{\mathrm{V}}(\sim 530.5 \mathrm{eV})$, and $\mathrm{O}_{\mathrm{C}}(\sim 532.2 \mathrm{eV})$, which correspond to lattice oxygen species, surface oxygen vacancies and chemisorbed oxygen species, respectively [14, 43]. It is found that the concentration of $\mathrm{Ce}^{3+}$ and $\mathrm{O}_{V}$ varied with the doping amount of lanthanum. Table 2 indicates $\mathrm{O}_{\mathrm{V}}$ levels are $26.75 \%, 29.35 \%, 28.83 \%, 28.51 \%$ and $27.57 \%$, corresponding to $\quad \mathrm{CeO}_{2}, \quad \mathrm{Ce}_{0.95} \mathrm{La}_{0.05} \mathrm{O}_{\delta}, \quad \mathrm{Ce}_{0.90} \mathrm{La}_{0.10} \mathrm{O}_{\delta}$, $\mathrm{Ce}_{0.85} \mathrm{La}_{0.15} \mathrm{O}_{\delta}$ and $\mathrm{Ce}_{0.80} \mathrm{La}_{0.20} \mathrm{O}_{\delta}$, respectively, which indicate that doping appropriate amount of lanthanum contributes to the increase of $\mathrm{Ce}^{3+}$ content on the catalyst surface, which is mainly because the chemical state of $\mathrm{La}^{3+}$ is different from that of $\mathrm{Ce}^{3+}$. After doping lanthanum, in order to maintain the overall electronegativity of $\mathrm{CeO}_{2}$, more trivalent cerium is produced, which leads to the increase of oxygen vacancies, which is consistent with the previous Raman results. In addition, the survey spectra of $\mathrm{Ce}_{1-\mathrm{x}} \mathrm{La}_{\mathrm{x}} \mathrm{O}_{\delta}$ composites are shown in Figure 8, there is no impurity peak except carbon, because the peak arrangement in the XPS spectra is performed using the characteristic peak of $\mathrm{C} 1 \mathrm{~s}$ as a reference (binding energy is $284.8 \mathrm{eV}$ ).

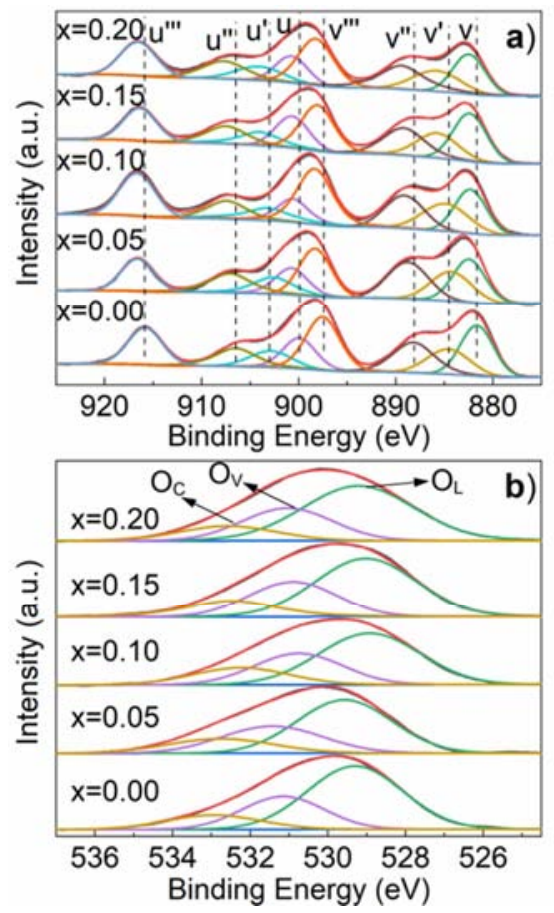

Figure 7. XPS spectra of the Ce $e_{1-x} L a_{x} O_{\delta}$ nanocomposites. (a) Ce 3d; (b) O 1s.
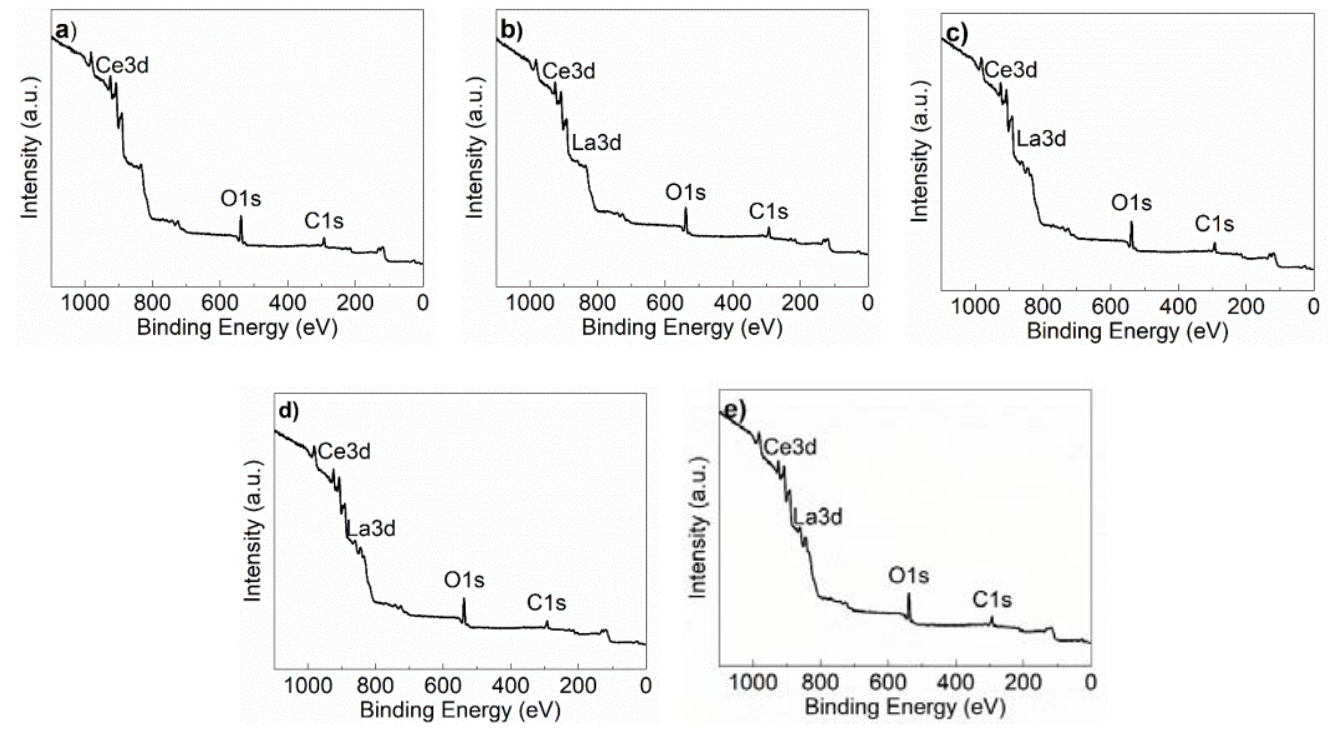

Figure 8. XPS survey of $C e_{1-x} L a_{x} O_{\delta}$ nanoparticles: (a) $x=0.00$, (b) $x=0.05$, (c) $x=0.10$, (d) $x=0.15$, (e) $x=0.20$. 
Table 2. Relative Ratios of the Surface Concentration of $\mathrm{Ce}^{3+}$ and Oxygen Vacancy Based on XPS Analysis.

\begin{tabular}{lll}
\hline Samples & $\begin{array}{l}\text { Concentration of } \\
\mathbf{C e}\end{array}$ & $\begin{array}{l}\text { Concentration of } \mathbf{O}_{\mathbf{V}} \\
(\mathbf{\%})\end{array}$ \\
\hline $\mathrm{CeO}_{2}$ & 17.54 & 26.75 \\
$\mathrm{Ce}_{0.95} \mathrm{La}_{0.05} \mathrm{O}_{\delta}$ & 21.13 & 29.35 \\
$\mathrm{Ce}_{0.90} \mathrm{La}_{0.10} \mathrm{O}_{\delta}$ & 20.34 & 28.83 \\
$\mathrm{Ce}_{0.85} \mathrm{La}_{0.15} \mathrm{O}_{\delta}$ & 19.32 & 28.51 \\
$\mathrm{Ce}_{0.80} \mathrm{La}_{0.20} \mathrm{O}_{\delta}$ & 18.18 & 27.57 \\
\hline
\end{tabular}

\subsection{Catalytic Performance}

The activity evaluation results of the $\mathrm{Ce}_{1-\mathrm{x}} \mathrm{La}_{\mathrm{x}} \mathrm{O}_{\delta}$ monolithic catalyst for catalyzing $\mathrm{CO}_{2}$ and methanol synthesis DMC are shown in Figure 9. It is carried out on a continuous tubular fixed-bed reactor. Firstly, $\mathrm{Ce}_{0.95} \mathrm{La}_{0.05} \mathrm{O}_{\delta}$ nanoparticles are chosen as the catalyst to synthesize DMC directly by introducing $\mathrm{CH}_{3} \mathrm{OH}$ and $\mathrm{CO}_{2}$ into the continuous tubular fixed-bed reactor. The catalytic performance of $\mathrm{Ce}_{0.95} \mathrm{La}_{0.05} \mathrm{O}_{\delta}$ nanoparticles coated on the honeycomb ceramics $\left(\mathrm{Ce}_{0.95} \mathrm{La}_{0.05} \mathrm{O}_{\delta}\right.$ monolithic catalyst $)$ is investigated under the condition of reaction temperatures of $100^{\circ} \mathrm{C} \sim 180^{\circ} \mathrm{C}$ and reaction pressure of $2.4 \mathrm{MPa}$ without any dehydrating agent. It is observed from Figure 9a that when the reaction temperature increases from $100{ }^{\circ} \mathrm{C}$ to $180^{\circ} \mathrm{C}$, the conversion of $\mathrm{CH}_{3} \mathrm{OH}$ increases firstly and then decreases slightly and it reaches the maximum of $22.01 \%$ when the reaction temperature is at $140^{\circ} \mathrm{C}$. Besides, as the temperature increases, by-products increase as well, and the selectivity of dimethyl carbonate gradually decreases, which mainly due to the observation of two competing and side reactions during the catalytic process: (1) $2 \mathrm{CH}_{3} \mathrm{OH} \rightarrow \mathrm{CH}_{3} \mathrm{OCH}_{3}+\mathrm{H}_{2} \mathrm{O}$ and (2) $\mathrm{CH}_{3} \mathrm{OH}+\mathrm{CO}_{2} \rightarrow$ $\mathrm{HCHO}+\mathrm{CO}+\mathrm{H}_{2} \mathrm{O}$. As the reaction temperature increases, the above two side reactions are promoted, resulting in more by-products (DME, HCHO and CO). [44-46, 19].

Furthermore, we compare the catalytic performance of the $\mathrm{Ce}_{0.95} \mathrm{La}_{0.05} \mathrm{O}_{\delta}$ monolithic catalyst with the $\mathrm{Ce}_{0.95} \mathrm{La}_{0.05} \mathrm{O}_{\delta}$ nanoparticle catalyst which are simply filled in a continuous tubular fix-bed reactor $\left(\mathrm{Ce}_{0.95} \mathrm{La}_{0.05} \mathrm{O}_{\delta}\right.$ granular catalyst, Figure 9b) as well. The $\mathrm{Ce}_{0.95} \mathrm{La}_{0.05} \mathrm{O}_{\delta}$, coated on the honeycomb ceramics, gives a higher $\mathrm{CH}_{3} \mathrm{OH}$ conversion (Figure 9a, black lines) and DMC selectivity (Figure 9a, red lines) than that of $\mathrm{Ce}_{0.95} \mathrm{La}_{0.05} \mathrm{O}_{\delta}$ granular catalyst at each reaction temperatures (e.g., $100-180^{\circ} \mathrm{C}$ ) in the direct dimethyl carbonate synthesis from carbon dioxide, indicating that the $\mathrm{Ce}_{0.95} \mathrm{La}_{0.05} \mathrm{O}_{\delta}$ monolithic catalyst give much better catalytic performance than the corresponding granular catalyst. This is mainly due to the following facts that the by-product water can be quickly detached from the surface of the monolithic catalyst during the reaction process, thus avoiding the catalyst activity reduction or even deactivation due to water poisoning. In all, the catalysts uniformly coated onto the honeycomb ceramics indeed can largely improve the catalytic performance (including the $\mathrm{CH}_{3} \mathrm{OH}$ conversion and selectivity toward target product dimethyl carbonate) in the direct dimethyl carbonate synthesis reactions investigated in the direct DMC synthesis at $140{ }^{\circ} \mathrm{C}$, Figure 10a. The catalytic activity of the $\mathrm{Ce}_{1-\mathrm{x}} \mathrm{La}_{\mathrm{x}} \mathrm{O}_{\delta}$ catalysts is $\mathrm{Ce}_{0.95} \mathrm{La}_{0.05} \mathrm{O}_{\delta}>$ $\mathrm{Ce}_{0.90} \mathrm{La}_{0.10} \mathrm{O}_{\delta}>\mathrm{Ce}_{0.85} \mathrm{La}_{0.15} \mathrm{O}_{\delta}>\mathrm{Ce}_{0.80} \mathrm{La}_{0.20} \mathrm{O}_{\delta}>\mathrm{CeO}_{2}$ with the DMC yield of $18.15 \%, 15.81 \%, 15.01,13.31$ and $12.34 \%$. Interestingly, a volcano-type curve of the catalytic activity is observed, the $\mathrm{Ce}_{0.95} \mathrm{La}_{0.05} \mathrm{O}_{\delta}$ nanocomposite catalyst shows the best catalytic activity with the highest $\mathrm{CH}_{3} \mathrm{OH}$ conversion of $22.01 \%$ and DMC selectivity of $82.53 \%$. Moreover, the activity of these $\mathrm{Ce}_{1-\mathrm{x}} \mathrm{La}_{\mathrm{x}} \mathrm{O}_{\delta}$ nanocomposites is closely related to the concentration of the surface $\left[\mathrm{O}_{\mathrm{C}}+\mathrm{O}_{\mathrm{V}}\right]$ species, consistent with the previous observation [14]. It is worth to note that the DMC selectivity is gradually decreases from $85.86 \%$ for $\mathrm{CeO}_{2}$ to $78.24 \%$ for $\mathrm{Ce}_{80} \mathrm{La}_{0.20} \mathrm{O}_{\delta}$ with the increasing lanthanum dopants. In general, $\mathrm{Ce}_{0.95} \mathrm{La}_{0.05} \mathrm{O}_{\delta}$ monolithic catalyst exhibits the highest $\mathrm{CH}_{3} \mathrm{OH}$ conversion and DMC productivity among all the lanthanum doped cerium oxide. Furthermore, Table 3 compares $\mathrm{Ce}_{0.95} \mathrm{La}_{0.05} \mathrm{O}_{\delta}$ monolithic catalyst with some previously reported granular catalysts. We note that $\mathrm{Ce}_{0.95} \mathrm{La}_{0.05} \mathrm{O}_{\delta}$ monolithic catalyst exhibits higher catalytic activity than that of cerium-based particulate catalysts without dehydrating agents and other commonly used catalyst in the literatures [8, 16, 20, 47, 48]. This is mainly attributed to the monolithic catalysts can reduce the interaction between catalyst and gas (including reactants and products) and remove the generated water in time, thus improving the catalytic activity.
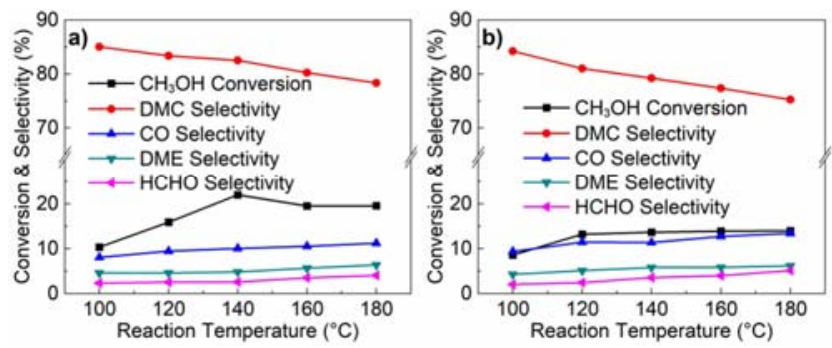

Figure 9. Comparison of the catalytic performance of the $\mathrm{Ce}_{0.95} \mathrm{La}_{0.05} \mathrm{O}_{\delta}$ catalyst ((a) coated on the honeycomb ceramics and (b) simply filled with 40-60 mesh) Reaction conditions: amount of catalyst $=500 \mathrm{mg}, \mathrm{CH}_{3} \mathrm{OH}$ : $\mathrm{CO}_{2}=2.0: 1.0$ (molar ratio), $P=2.4 \mathrm{MPa}, \mathrm{T}=140^{\circ} \mathrm{C}$ [14].

Table 3. Summary of reaction conditions and catalyst activity over various catalyst using fixed-bed reactor without dehydrating agents.

\begin{tabular}{|c|c|c|c|c|c|}
\hline Catalyst & $\mathbf{T}\left({ }^{\circ} \mathbf{C}\right)$ & $\mathbf{P}$ (MPa) & $\mathrm{CH}_{3} \mathrm{OH} \mathrm{Con}(\%)$ & DMC Sel. (\%) & Reference \\
\hline $\mathrm{Ti}_{0.04} \mathrm{Ce}_{0.96} \mathrm{O}_{2}$ & 140 & 1.0 & 5.4 & 83.1 & {$[16]$} \\
\hline $\mathrm{H}_{3} \mathrm{PW}_{12} \mathrm{O}_{40} / \mathrm{Ce}_{0.1} \mathrm{Ti}_{0.9} \mathrm{O}_{2}$ & 170 & - & 5.5 & 91.4 & [47] \\
\hline $\mathrm{Zr}_{0.10} \mathrm{Ce}_{0.90} \mathrm{O}_{2}$ & 140 & 7.5 & 11.2 & 9.6 & [48] \\
\hline $\mathrm{Cu}-\mathrm{CeO}_{2}$ & 170 & 5.0 & 0.9 & 2.0 & [49] \\
\hline $\mathrm{Cu}-\mathrm{Ni} /$ molecular sieve & 120 & 1.1 & 5.8 & 86.0 & [8] \\
\hline $\mathrm{Cu}_{\mathrm{x}} \mathrm{Ni}_{\mathrm{y}} @ \mathrm{POP}-\mathrm{PPh}_{3}$ & 160 & 2.4 & 10.5 & 80.0 & [20] \\
\hline $\mathrm{CuNi} / \mathrm{ZIF}-8$ & 110 & 2.0 & 12.8 & 50.0 & [19] \\
\hline
\end{tabular}


Durability is one of the most significant parameters to evaluate the catalytic performance of a catalyst. Therefore, we have tested the durability of the $\mathrm{Ce}_{0.95} \mathrm{La}_{0.05} \mathrm{O}_{\delta}$ monolithic catalyst prepared in this experiment as well. It is continuously examined more than 115 hours under $140^{\circ} \mathrm{C}$ and $2.4 \mathrm{MPa}$ and the test result is noted in Figure 10b. It shows the $\mathrm{CH}_{3} \mathrm{OH}$ conversion and DMC selectivity are almost constant at $\sim 22 \%$ and $\sim 80 \%$, respectively, and no deactivation is observed during the catalytic test of the initial 100 hours, which indicates that the durability of the $\mathrm{Ce}_{0.95} \mathrm{La}_{0.05} \mathrm{O}_{\delta}$ monolithic catalyst is as high as 100 hours, which is much higher than that of $\mathrm{Cu}_{1} \mathrm{Ni}_{1} @$ POP-PPh monolithic catalyst (about 16 hours) [20] and $\mathrm{Ti}_{0.1} \mathrm{Ce}_{0.9} \mathrm{O}_{2}$ monolithic catalyst (less than 50 hours) [14]. However, after the 100 hours' catalytic reaction, the conversion of $\mathrm{CH}_{3} \mathrm{OH}$ and the selectivity of DMC decrease slightly to $20 \%$ and $76 \%$, respectively. This phenomenon is a result of the formation of carbonates covering the catalyst surface [14] in the long-time reaction. Therefore, we can find that the doping of lanthanum can significantly improve the stability and durability of the cerium-based composite oxide catalyst in the direct dimethyl carbonate synthesis process.
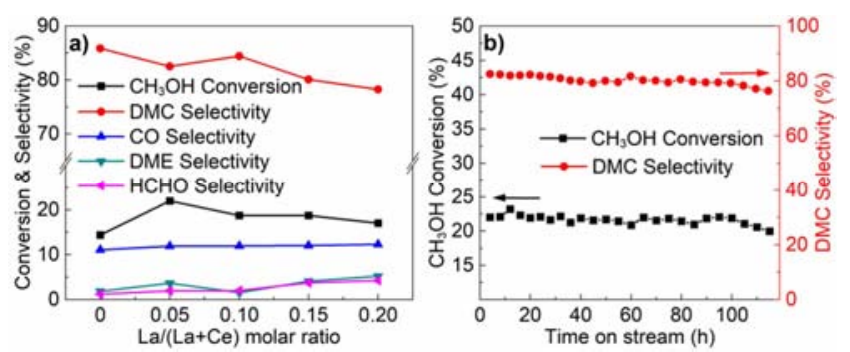

Figure 10. (a) Catalytic performance over the $C e_{1-x} L a_{x} O_{\delta}$ monolithic catalysts in DMC direct synthetic reaction. (b) Durability test of $C e_{0.95} L a_{0.05} O_{\delta}$ monolithic catalyst for a long time of over 115 hours. Reaction conditions: amount of catalyst $=500 \mathrm{mg}, \mathrm{CH}_{3} \mathrm{OH}: \mathrm{CO}_{2}=2.0: 1.0$ (molar ratio), $P=2.4$ $\mathrm{MPa}, \mathrm{T}=140^{\circ} \mathrm{C}[14]$

\section{Conclusions and Recommendation}

In general, we have designed and prepared five kinds of La-doped spherical ceria nanoparticles via a co-precipitation method. $\mathrm{H}_{2}$-TPR, XPS and Raman spectra tests show that the introduction of lanthanum species has a certain effect on the surface oxygen vacancy sites of these $\mathrm{Ce}_{1-\mathrm{x}} \mathrm{La}_{\mathrm{x}} \mathrm{O}_{\delta}$ nanocomposites. Besides, higher oxygen vacancy sites concentration is beneficial to the adsorption of $\mathrm{CO}_{2}$ and improves the catalytic performance of DMC direct synthetic method. In addition, we also found that an appropriate amount of lanthanum doping into $\mathrm{CeO}_{2}$ can significantly improve the reaction stability and durability. The $\mathrm{Ce}_{0.95} \mathrm{La}_{0.05} \mathrm{O}_{\delta}$ monolithic catalyst can maintain high activity for more than 100 hours without obviously deactivation under the optimal reaction temperature $\left(140^{\circ} \mathrm{C}\right)$.

Based on the above results and conclusions, the following suggestions are put forward.

This paper focuses on the experimental study of the effect of reaction conditions on the catalytic activity, without considering the internal mechanism of the reaction. It is recommended to consider the reaction mechanism of the reaction in the later research, and reveal the internal connection between the catalytic activity and the structure of the catalyst by studying the reaction mechanism.

\section{References}

[1] D'Alessandro, D. M. Smit, B. and Long, J. R. (2010) Carbon Dioxide Capture: Prospects for New Materials. Angew. Chem. Int. Ed., 49, 6058-6082.

[2] Souza, L. F. S. Ferreira, P. R. R. de Medeiros, J. L. Alves, R. M. B. and Araújo, O. Q. F. (2014) Production of DMC from $\mathrm{CO}_{2} \quad$ via Indirect Route: Technical-Economical-Environmental Assessment and Analysis. ACS Sustain. Chem. Eng., 2, 62-69.

[3] Keller, N. Rebmann, G. and Keller, V. (2009) Catalysts, mechanisms and industrial processes for the dimethylcarbonate synthesis. J. Mol. Catal. A: Chem., 317, 1-18.

[4] Ono and Y. (1997) Dimethyl carbonate for environmentally benign reactions. Catal. Today, 35, 15-25.

[5] Liu, B. Li, C. M. Zhang, G. Q. Yao, X. S. Chuang, S. S. C. and Li, Z. (2018) Oxygen Vacancy Promoting Dimethyl Carbonate Synthesis from $\mathrm{CO}_{2}$ and Methanol over $\mathrm{Zr}$-doped $\mathrm{CeO}_{2}$ Nanorods. ACS Catal., 8, 10446-10456.

[6] Song, Y. He, X. Yu, B. Li, H. and He, L. (2020) Protic ionic liquid-promoted synthesis of dimethyl carbonate from ethylene carbonate and methanol. Chin. Chem. Lett., 31, 667-672.

[7] Tamboli, A. H. Chaugule, A. A. and Kim, H. (2017) Catalytic developments in the direct dimethyl carbonate synthesis from carbon dioxide and methanol. Chem. Eng. J., 323, 530-544.

[8] Chen, H. L. Wang, S. J. Xiao, M. Han, D. M. and Lu, Y. X. (2012) Direct Synthesis of Dimethyl Carbonate from $\mathrm{CO}_{2}$ and $\mathrm{CH}_{3} \mathrm{OH}$ Using $0.4 \mathrm{~nm}$ Molecular Sieve Supported $\mathrm{Cu}-\mathrm{Ni}$ Bimetal Catalyst. Chin. J. Chem. Eng., 20, 906-913.

[9] Woo, J. M. Seo, J. Y. Kim, H. Lee, D. H. and Moon, J. H. (2018) $\mathrm{CuY}$ Zeolite Catalysts Prepared by Ultrasonication-assisted Ion-exchange for Oxidative Carbonylation of Methanol to Dimethyl Carbonate. Ultrason. Sonochem., 44, 146-151.

[10] Engeldinger, J. Richter, M. and Bentrup, U. (2011) Mechanistic investigations on dimethyl carbonate formation by oxidative carbonylation of methanol over a CuY zeolite: An operando SSITKA/DRIFTS/MS study. Phys. Chem. Chem. Phys., 14, 2183-2191.

[11] Stoica, G. Abelló, S. and Pérez-Ramírez, J. (2009) Na-dawsonite derived aluminates for DMC production by transesterification of ethylene carbonate. Appl. Catal. A Gen, $365,252-260$.

[12] Xu, J. Long, K. Z. Chen, T. Xue, B. Li, Y. X. and Cao, Y. (2013) Mesostructured graphitic carbon nitride as a new base catalyst for the efficient synthesis of dimethyl carbonate by transesterification. Catal. Sci. Technol., 3, 3192-3199.

[13] Joe, W. Lee, H. J. Hong, U. G. Ahn, Y. S. Song, C. J. Kwon, B. J. and Song, I. K. (2012) Urea methanolysis to dimethyl carbonate over $\mathrm{ZnO}-\mathrm{CeO}_{2}-\mathrm{MO}\left(\mathrm{MO}: \mathrm{La}_{2} \mathrm{O}_{3}, \mathrm{Y}_{2} \mathrm{O}_{3}, \mathrm{Co}_{2} \mathrm{O}_{3}\right.$, $\mathrm{Ga}_{2} \mathrm{O}_{3}$, and $\mathrm{ZrO}_{2}$ ) catalysts. J. Ind. Eng. Chem., 18, 1730-1735. 
[14] Chen, Y. D. Wang, H. Qin, Z. X. Tian, S. L. Ye, Z. B. Abroshan, H. and Li, G. (2019) $\mathrm{Ti}_{\mathrm{x}} \mathrm{Ce}_{1-\mathrm{x}} \mathrm{O}_{2}$ nanocomposites: a monolithic catalyst for the direct conversion of carbon dioxide and methanol to dimethyl carbonate. Green Chem., 21, 4642-4649.

[15] Xuan, K. Pu, Y. Li, F. Li, A. Luo, J. Li, L. Wang, F. Zhao, N. and Xiao, F. (2018) Direct synthesis of dimethyl carbonate from $\mathrm{CO}_{2}$ and methanol over trifluoroacetic acid modulated UiO-66. J. $\mathrm{CO}_{2}$. Util., 27, 272-282.

[16] Fu, Z. W. Zhong, Y. Y. Yu, Y. H. Long, L. Z. Xiao, M. Han, D. M. Wang, S. J. and Meng, Y. Z. (2018) $\mathrm{TiO}_{2}$ Doped $\mathrm{CeO}_{2}$ Nanorod Catalyst for Direct Conversion of $\mathrm{CO}_{2}$ and $\mathrm{CH}_{3} \mathrm{OH}$ to Dimethyl Carbonate: Catalytic Performance and Kinetic Study. ACS Omega, 3, 198-207.

[17] (2014) Review for the Direct Synthesis of Dimethyl Carbonate. Chembioeng, 1, 214-229.

[18] Pimprom, S. Sriboonkham, K. Dittaneta, P. Föttinger, K. Rupprechter, G. and Kongkachuichay, P. (2015) Synthesis of copper-nickel/SBA-15 from rice husk ash catalyst for dimethyl carbonate production from methanol and carbon dioxide. $J$. Ind Eng. Chem., 31, 156-166.

[19] Poungsombate, A. Imyen, T. Dittanet, P. Embley, B. and Kongkachuichay, P. (2017) Direct synthesis of dimethyl carbonate from $\mathrm{CO}_{2}$ and methanol by supported bimetallic $\mathrm{Cu}-$ Ni/ZIF-8 MOF catalysts. J. Taiwan. Inst. Chem. Eng., 80, $16-24$.

[20] Chen, Y. D. Yang, Y. Tian, S. L. Ye, Z. B. Tang, Q. Ye, L. and Li, G. (2019) Highly effective synthesis of dimethyl carbonate over CuNi alloy nanoparticles@Porous organic polymers composite. Appl. Catal. A Gen., 587, 117275.

[21] Choi, J. C. Kohno, K. Ohshima, Y. Yasuda, H. and Sakakura, T. (2008) Tin- or titanium-catalyzed dimethyl carbonate synthesis from carbon dioxide and methanol: Large promotion by a small amount of triflate salts. Catal. Commun., 9, 1630-1633.

[22] Akune, T. Morita, Y. Shirakawa, S. Katagiri, K. and Inumaru, K. (2018) $\mathrm{ZrO}_{2}$ Nanocrystals as Catalyst for Synthesis of Dimethylcarbonate from Methanol and Carbon Dioxide: Catalytic activity and Elucidation of Active Sites. Langmuir, 34, 23-29.

[23] Stoian, D. Medina, F. and Urakawa, A. (2018) Improving the stability of $\mathrm{CeO}_{2}$ catalyst by rare earth metal promotion and molecular insights in the dimethyl carbonate synthesis from $\mathrm{CO}_{2}$ and methanol with 2-cyanopyridine. ACS Catal., 8, 3181-3193.

[24] Zhao, S. Y. Wang, S. P. Zhao, Y. J. and Ma, X. B. (2017) An in situ infrared study of dimethyl carbonate synthesis from carbon dioxide and methanol over well-shaped $\mathrm{CeO}_{2}$. Chin. Chem. Lett., 28, 65-69.

[25] Hofmann, H. J. Brandner, A. and Claus, P. (2012) Direct Synthesis of Dimethyl Carbonate by Carboxylation of Methanol on Ceria-Based Mixed Oxides. Chem. Eng. Technol., $35,2140-2146$

[26] Kumar, P. With, P. Srivastava, V. C. Gläser, R. and Mishra, I. M. (2016) Efficient ceria-zirconium oxide catalyst for carbon dioxide conversions: Characterization, catalytic activity and thermodynamic study. J. Alloys Compd., 696, 718-726.

[27] Wang, S. P. Zhao, L. F. Wang, W. Zhao, Y. J. Zhang, G. L. Ma, X. B. and Gong, J. L. (2013) Morphology control of ceria nanocrystals for catalytic conversion of $\mathrm{CO}_{2}$ with methanol.
Nanoscale, 5, 5582-5590.

[28] Kang, K. H. Joe, W. Chang, H. L. Kim, M. Dong, B. K. Jang, B and Song, I. K. (2013) Direct synthesis of dimethyl carbonate from methanol and carbon dioxide over $\mathrm{CeO}_{2}(\mathrm{X})-\mathrm{ZnO}(1-\mathrm{X})$ nano-catalysts. J. Nanosci. Nanotechno., 13, 8116-8120.

[29] Kumar, P. Chandra, V. Srivastavaa Gläser, R. With, P. and Mishra, I. M. (2017) Active ceria-calcium oxide catalysts for dimethyl carbonate synthesis by conversion of $\mathrm{CO}_{2}$. Powder Technol., 309, 13-21.

[30] Liu, B. Li, C. M. Zhang, G. Q. Yan, L. F. and Li, Z. (2017) Direct synthesis of dimethyl carbonate from $\mathrm{CO}_{2}$ and methanol over $\mathrm{CaO}-\mathrm{CeO}_{2}$ catalysts: the role of acid-base properties and surface oxygen vacancies. New J. Chem., 41, 12231-12240.

[31] Tomašić, V. and Jović, F. (2006) State-of-the-art in the monolithic catalysts/reactors. Appl. Catal. A Gen., 311, 112-121.

[32] Sandeeran, G. and Holger, F. (2017) Monoliths: A Review of the Basics, Preparation Methods and Their Relevance to Oxidation. Catalysts, 7, 62-90.

[33] Chen, A. L. Zhou, Y. Ta, N. Li, Y. and Shen, W. (2015) Redox properties and catalytic performance of ceria-zirconia nanorods. Catal. Sci. Technol., 5, 4184-4192.

[34] Wang, R. G. Mutinda, S. I. and Fang, M. H. (2013) One-pot hydrothermal synthesis and high temperature thermal stability of $\mathrm{Ce}_{\mathrm{x}} \mathrm{Zr}_{1-\mathrm{x}} \mathrm{O}_{2}$ nanocrystals. RSC Adv., 3, 19508-19514.

[35] Qiao, B. T. Liu, J. X. Wang, Y. G. Lin, Q. Q. and Liu, J. Y. (2015) Highly Efficient Catalysis of Preferential Oxidation of $\mathrm{CO}$ in $\mathrm{H}_{2}$-Rich Stream by Gold Single-Atom Catalysts. $A C S$ Catal., 5, 150917155511007.

[36] Hamid, M. Y. S. Firmansyah, M. L. Triwahyono, S. Jalil, A. A. Mukti, R. R. Febriyanti, E. Suendo, V. Setiabudi, H. D. Mohamed, M. and Nabgan, W. (2017) Oxygen vacancy-rich mesoporous silica $\mathrm{KCC}-1$ for $\mathrm{CO}_{2}$ methanation. Appl. Catal. A Gen., 532, 86-94.

[37] Fei, Z. Y. Xie, X. Yong, D. Liu, H. Y. Xian, C. Tang, J. H. Cui, M. F. and $\mathrm{Xu}$, Q. (2014) $\mathrm{HCl}$ Oxidation for Sustainable $\mathrm{Cl}_{2}$ Recycle over the $\mathrm{Ce}_{\mathrm{x}} \mathrm{Zr}_{1-\mathrm{x}} \mathrm{O}_{2}$ Catalysts: Effects of Ce/Zr Ratio on Activity and Stability. Ind. Eng. Chem. Res., 53, 19438-19445.

[38] Liu, X. Ding, J. Lin, X. Gao, R. H. Li, Z. H. and Dai, W. L. (2015) $\mathrm{Zr}$-doped $\mathrm{CeO}_{2}$ nanorods as versatile catalyst in the epoxidation of styrene with tert-butyl hydroperoxide as the oxidant. Appl. Catal. A Gen., 503, 117-123.

[39] Reddy, B. M. Rao, K. N. and Bharali, P. (2009) Copper Promoted Cobalt and Nickel Catalysts Supported on Ceria Alumina Mixed Oxide: Structural Characterization and CO Oxidation Activity. Ind. Eng. Chem. Res., 48, 8478-8486.

[40] Rao, K. N. Reddy, B. M. and Park, S. E. (2009) Superior copper promoted bimetallic catalysts for chemoselective hydrogenation of ortho-chloro-nitrobenzene. Catal. Commun., $11,142-145$.

[41] Benjaram, M. R. Katta, L. and Thrimurthulu, G. (2010) Novel Nanocrystalline $\mathrm{Ce}_{1^{-} \mathrm{x}} \mathrm{La}_{\mathrm{x}} \mathrm{O}_{2-\delta} \quad(\mathrm{x}=0.2) \quad$ Solid Solutions: Structural Characteristics and Catalytic Performance. Chem. Mater., 22, 467-475. 
[42] Zhang, Y. Yuwono, A. H. Wang, J. and Li, J. (2009) Enhanced Photocatalysis by Doping Cerium into Mesoporous Titania Thin Films. J. Phys. Chem. C, 113, 21406-21412.

[43] Wang, X. Jiang, Z. Y. Zheng, B. J. Xie, Z. X. and Zheng, L. S. (2012) Synthesis and shape-dependent catalytic properties of $\mathrm{CeO}_{2}$ nanocubes and truncated octahedra. CrystEngComm, 14, 7579-7582.

[44] Bian, J. Xiao, M. Wang, S. Wang, X. Lu, Y. and Meng, Y. (2009) Highly effective synthesis of dimethyl carbonate from methanol and carbon dioxide using a novel copper-nickel/graphite bimetallic nanocomposite catalyst. Chemical Engineering Journal, 147, 287-296.

[45] Zhang, Z. F. Liu, Z. W. Lu, J. and Liu, Z. T. (2011) Synthesis of Dimethyl Carbonate from Carbon Dioxide and Methanol over $\mathrm{Ce}_{\mathrm{x}} \mathrm{Zr}_{1-\mathrm{x}} \mathrm{O}_{2}$ and [EMIM] $\mathrm{Br} / \mathrm{Ce}_{0.5} \mathrm{Zr}_{0.5} \mathrm{O}_{2}$. Industrial \& Engineering Chemistry Research, 50.

[46] Saada, R. Kellici, S. Heil, T. Morgan, D. and Saha, B. (2015)
Greener synthesis of dimethyl carbonate using a novel ceriazirconia oxide/graphene nanocomposite catalyst. Applied Catalysis B Environmental, s 168-169, 353-362.

[47] Chiang, C. L. Lin, K. S. Yu, S. H. and Lin, Y. G. (2017) Synthesis and characterization of $\mathrm{H}_{3} \mathrm{PW}_{12} \mathrm{O}_{40} / \mathrm{Ce}_{0.1} \mathrm{Ti}_{0.9} \mathrm{O}_{2}$ for dimethyl carbonate formation via Methanol carbonation. Int. J. Hydrogen Energ., 42, 22108-22122.

[48] Tamboli, A. H. Chaugule, A. A. Gosavi, S. W. and Kim, H. (2018) $\mathrm{Ce}_{\mathrm{x}} \mathrm{Zr}_{1-\mathrm{x}} \mathrm{O}_{2}$ solid solutions for catalytic synthesis of dimethyl carbonate from $\mathrm{CO}_{2}$ : Reaction mechanism and the effect of catalyst morphology on catalytic activity. Fuel, 216, 245-254.

[49] Marciniak, A. A. Alves, O. C. Appel, L. G. and Mota, C. J. A. (2019) Synthesis of dimethyl carbonate from $\mathrm{CO}_{2}$ and methanol over $\mathrm{CeO}_{2}$ : Role of copper as dopant and the use of methyl trichloroacetate as dehydrating agent. Journal of Catalysis, 371, 88-95. 